\title{
MATERNAL BAĞLANMA DÜZEYİ VE ETKILEYEN FAKTÖRLER
}

\section{EVALUATION OF THE RELATIONSHIP BETWEEN MATERNAL ATTACHMENT LEVELS OF MOTHERS AND AFFECTING FACTORS}

\author{
Kevser ÇİMEN ${ }^{1}$, Handan VAROL ${ }^{1}$ \\ ${ }^{1}$ SakaryaÜniversitesi, SağlıkBilimleri Enstitüsü, Sakarya, Türkiye \\ Kevser Çimen https://orcid.org/0000-0001-8198-9305 \\ Handan Varol https://orcid.org/0000-0003-4092-5836
}

\begin{abstract}
Özet
Amaç: Bu çalışmada, doğum sonu dönemde maternal bağlanma düzeyinin belirlenmesi ve etkileyen faktörlerin incelenmesi amaçlanmıştır.

Yöntem: Tanımlayıcı ve kesitsel tipte bir araştırma olarak planlanan bu çalışmanın örneklemini Ocak Şubat 2020 tarihleri arasında Sakarya ili Sakarya Eğitim ve Araştırma Hastanesi lohusa servisinde yatmakta olan, vajinal ve sezaryen doğum yapan 340 anne oluşturmaktadır. Maternal bağlanmayı ölçmek amacı ile Muller tarafından geliştirilen Maternal Bağlanma Ölçeği kullanılmıştır. Veriler, bilgisayar ortamında, SPSS (versiyon 21.0) İstatistik Paket programında değerlendirilmiştir. Analizler için student T testi, One Way Anova testi ve çoklu karşılaştırmalar için Bonferroni testi kullanılmıştır. İstatistiksel anlamlılık değeri $\mathrm{p}<0.05$ kabul edilmiştir.

Bulgular: Çalışma grubunu oluşturanların yaşları 18 50 arasında değişmekte olup, ortalama $27.87 \pm 6.02$ y1l idi. Kadınların Maternal Bağlanma Ölçeği'nden aldıkları puan ortalamas $197.92 \pm 65.93$ olarak belirlendi. Yaşı 35 ve üzeri olanlarda, eğitim durumu ilkokul olanlarda, geniş ailede yaşayanlarda, gelir durumu dengeli olanlarda, doğum sürecini çok rahat ve kolay olarak tanımlayanlarda, ilk $10 \mathrm{dk}$ içinde bebeğini kucağına alanlarda ve bebeğinin bakımı konusunda endișe yaşamayanlarda, istatistiksel olarak anlamlı bir şekilde maternal bağlanma daha yüksek bulunmuştur $(\mathrm{p}<0.05)$.

Sonuç: Çalışma grubunda maternal bağlanma düzeyi oldukça yüksek belirlenmiştir. Maternal bağlanma düzeyinin yaş, eğitim durumu, aile tipi, ekonomik durum, doğum süreci, bebek ile ilk temas ve bebek bakımı ile endişelerden etkilendiği belirlenmiştir.
\end{abstract}

Anahtar Kelimeler: Maternal bağlanma, doğum sonu süreç, etkileyen faktörler

\begin{abstract}
Objective: In this study, detection of maternal bonding level and analyzing factors which impact the attachment have been aimed.
\end{abstract}

Method: The sample of this study, which is planned as a descriptive and cross-sectional type of research, consists of 340 mothers who were in the maternity ward of Sakarya Education and Research Hospital in Sakarya province between January and February 2020 and who gave birth vaginally and by cesarean section. On the purpose of assesment the maternal bond; Maternal Bonding Scale, which was developed by muller, have been used. The data was evaluated in the SPSS (version 21.0) Statistical Package program in a computer environment. Student T test, One Way Anova test and Bonferroni test were used for multiple comparisons. The statistical significance value of $\mathrm{p}<0.05$ was accepted

Results: The age of people who consist study group showed differency between 18 - 50 and it's average was $27.87 \pm 6.02$. Average score of women took from the scale was determined as $97.92 \pm 65.93$. Statistically significant maternal attachment was found in those aged 35 and over, with educational status in primary school, living in extended families, with balanced in comes, who describe the birth process as very comfortable and easy, who held their baby in the first 10 minutes and who did not have concerns about the care of their baby $(\mathrm{p}<0.05)$.

Conclusion: In the study group, maternal bonding level determined extremly high. As a result of this study, a numerous of concerns impact maternal attachment level such as age, education background, family type, economical situation, birth process, first contact with baby and baby care.

Keywords: Maternal bonding, after the birth process, maternal bonding scale 


\section{GİRIŞ}

Maternal bağlanma, anne ile bebek arasında gelişen, süreklilik ve değişkenlik gösteren, yoğun duygusal süreci barındıran, davranışsal ve emosyonel bir bağlanma türüdür. Maternal bağlanma ağır ve uzun bir süreci ele alır. $\mathrm{Bu}$ bağlanma bebeğin fiziksel, sosyal ve psikolojik gelişimi üzerinde etkilidir (1). Maternal bağlanma annenin fetüsün varlığını öğrendiği ilk anda başlamaktadır. Gebelik sürecinde annenin fetüsün varlığını kabul etmesi, benimsemesi ve fetüs ile iletişime geçmesi maternal bağlanma sürecine pozitif etki etmektedir. Postpartum dönem ise maternal bağlanmanın en yoğun olarak yaşanmaya başlandığı dönemdir. Bu dönemde anne ve bebek arasındaki iletişimin erken başlaması, annelerin annelik rolünü benimsemesi ve bebeğe bağlanması kaliteli ebeveyn olmasını sağlamaktadır (2).

Anne - bebek bağlanması gebelik, doğum ve doğum sonrası dönemde gelişme gösterir ve anne - bebek ilişkisi devam ettikçe desteklenir (3). Doğum öncesi düşük bağlanma düzeylerinin postpartum bağlanma sorunlarına sebep olduğu ve annede daha yüksek depresif belirtilere neden olmasından dolayı çocuğun gelecekteki duygusal, bilişsel ve fiziksel gelişiminde önemli bir rol oynadığı belirtilmiştir (4-6). Anne bebek bağlanmasına etki eden doğum sürecinde ise annenin bebeğine ilk dokunuşuyla annede olumlu duygular uyanır ve ebeveynlik tutumları gelişerek bağlanmaya destek olabilmektedir (7-9). Emzirme ile de anne bebek arası olumlu bağlar kurulur. Daha uzun süre emzirilen çocukların anneleri tarafindan daha "sevimli ve sicak" bulunduğu da ifade edilmiştir (10).

Annenin içinde bulunduğu şartlar maternal bağlanma sürecini pozitif veya negatif etkileyebilmektedir. Gebeliğin planlanan bir durum olup olmaması, gebeliğin istenmesi, yaş, prematüre doğum, tensel temasın doğru zamanda başlatılması, eğitim durumu, gelir durumu, gebelik sayısı, eş ilişkileri, eş desteği, annenin kendisine duyduğu güven duygusu, yaşayan çocuk sayısı ve gebelik haftası annelerin bağlanma düzeyi üzerine etki eden maternal faktörlerdendir $(2,11)$.

Maternal bağlanma sürecinde bebekte güven duygusu oluşur. Anne ve bebek arasında kurulan ilk temas ve emzirme bebek için bu güven duygusunun kazanılmasında önem arz etmektedir. Fiziksel ve duygusal olarak ihtiyaçları karşılanmayan bebeklerin; çocukluk, ergenlik ve yetişkinlik dönemlerinde bağlanma ve güven duygusunda sorun yaşadığı, fiziksel, sosyal ve psikolojik alanda geri kaldığı saptanmıştır (12). Anne ile bebek arasında gelişen ve eşsiz olan bağlanmanın oluşumunda hemşire ve ebeler 
anahtar role sahiptir. Sağlık bakım profesyonellerinin anne bebek arasındaki bağlanmayı güçlendirmek için riskli grupları gözlemleyip değerlendirmeleri ve destekleyici bakım ve danışmanlık vermeleri yarar sağlayacaktır $(12,13)$.

$\mathrm{Bu}$ çalışma, doğum sonu dönemde maternal bağlanma düzeyinin belirlenmesi ve etkileyen faktörlerin incelenmesi amaciyla planlanmıştır.

\section{YÖNTEM}

Araştırma, doğum sonu dönemde maternal bağlanma ve etkileyen faktörleri incelemek amacıyla tanımlayıcı ve kesitsel tipte bir araştırma olarak planlanmıştır.

\section{Araştırmanın Yeri ve Zamanı}

Araştırma verileri Ocak - Şubat 2020 tarihleri arasında Sakarya ili Sakarya Eğitim ve Araştırma Hastanesi lohusa servisinde toplanmıştır.

\section{Araştırmanın Evren ve Örneklemi}

Araştırmanın evrenini Ocak - Şubat 2020 tarihleri arasında Sakarya ili Sakarya Eğitim ve Araştırma Hastanesi lohusa servisinde yatmakta olan, vajinal ve sezaryen doğum yapan kadınlar oluşturmaktadır. Araştırmanın örneklemini ise belirtilen tarihler arasında (Ocak- Şubat 2020) araştırmaya katılmayı kabul eden 340 anne oluşturmaktadır.

\section{Veri Toplama Araçları}

Çalışmanın amacına uygun olarak literatürden faydalanılarak hazırlanan anket formu ve Maternal Bağlanma Ölçeği kullanılarak, yüz yüze görüşme tekniği ile toplanmıştır (14-17). Anket formunda gebenin yaşı, eğitim düzeyi, mesleği gibi sosyodemografik özelliklerini içeren 5 soru; doğum şekli, doğum sayısı gibi obstetrik özelliklerini içeren 9 soru bulunmaktadır.

\section{Maternal Bağlanma Ölçeği}

Maternal bağlanmayı ölçmek amacı ile Muller tarafından 1994 yılında geliştirilmiş, Cronbach alpha değeri 0.85 olarak bulunmuştur. Ölçeğin Türkiye'ye geçerliği ve güvenirliği 2009 yılında Kavlak ve Şirin tarafından yapılmıştır (18). Ölçek dörtlü Likert tipte olmakta ve 26 maddeden oluşmaktadır. Ölçekten alınan en düşük puan 29, en yüksek puan ise 104 olup, puan arttıkça maternal bağlanma da artmaktadır. Bizim çalışmamızda ise Cronbach alpha değeri 0.85 olarak hesaplanmıştır.

\section{Araștırmanın Etik Yönü}

Araştırmanın yapılabilmesi için ilgili kurumlardan izin alınmıştır. Çalışma grubunu oluşturan gebelere ise araştırmanın amacı açıklanıp sözlü ve yazılı onam alındıktan sonra kabul eden annelerle anket doldurulmuştur. Çalışma verileri Helsinki Bildirgesi'ne uygun olarak toplanıp, araştırma ve yayın etiğine uyulmuştur. 


\section{İstatistiksel Analiz}

Veriler, bilgisayar ortamında, SPSS (versiyon 21.0) İstatistik Paket programında değerlendirilmiştir. Analizler için student T testi, One Way Anova testi, çoklu karşılaştırmalar için Bonferroni testi kullanılmıştır. İstatistiksel anlamlılık değeri $\mathrm{p}<0.05$ kabul edilmiştir.

\section{BULGULAR}

Çalışma grubunu oluşturanların yaşları 1850 arasında değişmekte olup, ortalama $27.87 \pm 6.02$ yıl idi. Kadınların öğrenim durumu \%29.7 lise olarak belirlenirken, \%78.8'inin gelir getirici herhangi bir işte çalışmadığı belirlendi. Gelir durumları sorgulandığında kadınların \%69.4’ü gelir gidere göre dengeli cevabını verdi. Gebelik sayıları ortalama $2.32 \pm 1.03$ olarak bulundu.

Kadınların Maternal Bağlanma Ölçeği'nden aldıkları puan ortalaması $97.92 \pm 65.93$ olarak belirlendi. Maternal bağlanmayı etkilediği düşünülen sosyodemografik özellikler Tablo 1'de verilmiştir.

Annelerin gebelik sayıları 1-4 arasında değişmekte olup, ortalama $2.33 \pm 2.33$ idi. Annelerin gebelik ile ilgili özelliklerine yönelik bilgiler Tablo 2'de verilmiştir.

Tablo 1. Maternal Bağlanma Ölçeği İle İlişkisi Olduğu Düşünülen Bazı Sosyodemografik Özellikler

\begin{tabular}{|c|c|c|c|c|c|}
\hline \multirow{2}{*}{$\begin{array}{c}\text { Sosyodemografik } \\
\text { özellikler }\end{array}$} & \multirow[b]{2}{*}{$\mathbf{n}$} & \multicolumn{4}{|c|}{ Maternal Bağlanma Ölçeği } \\
\hline & & Puan & $\begin{array}{c}\text { Test } \\
\text { değeri } \\
\mathrm{F} / \mathrm{T} ; \mathrm{p}\end{array}$ & $\begin{array}{c}\text { Çoklu } \\
\text { karşılaştırma }\end{array}$ & $\mathbf{p}$ \\
\hline \multicolumn{6}{|l|}{ Yaş } \\
\hline$\leq 24$ & 108 & $96.81 \pm 6.31$ & \multirow{6}{*}{$5.425 ; 0.001$} & $3-4$ & 0.275 \\
\hline $25-29 \quad(2)$ & 98 & $97.86 \pm 5.98$ & & $3-1$ & 0.351 \\
\hline $30-34 \quad(3)$ & 89 & $98.20 \pm 5.11$ & & $3-2$ & 0.978 \\
\hline$\geq 35$ & 45 & $100.13 \pm 5.93$ & & $4-1$ & 0.008 \\
\hline- & & & & $4-2$ & 0.138 \\
\hline- & & & & $1-2$ & 0.580 \\
\hline \multicolumn{6}{|l|}{ Eğitim durumu } \\
\hline İlkokul (1) & 98 & $99.50 \pm 5.74$ & \multirow{5}{*}{$5.425 ; 0.001$} & $3-4$ & 0.991 \\
\hline Ortaokul (2) & 94 & $98.43 \pm 5.94$ & & $3-1$ & 0.003 \\
\hline Lise & 101 & $96.64 \pm 6.25$ & & $3-2$ & 0.143 \\
\hline Üniversite (4) & 47 & $96.34 \pm 4.60$ & & $4-1$ & 0.013 \\
\hline- & & & & $4-2$ & 0.187 \\
\hline
\end{tabular}




\begin{tabular}{|c|c|c|c|c|c|}
\hline- & & & & $1-2$ & 0.577 \\
\hline \multicolumn{6}{|l|}{ Çalışma durumu } \\
\hline Çalışmıyor & 268 & $97.85 \pm 6.13$ & \multirow{2}{*}{$\begin{array}{l}1.071 ; \\
0.677\end{array}$} & - & - \\
\hline Çalışıyor & 72 & $98.15 \pm 5.26$ & & - & - \\
\hline \multicolumn{6}{|l|}{ Aile tipi } \\
\hline Çekirdek aile & 372 & $97.82 \pm 6.15$ & \multirow{2}{*}{$\begin{array}{c}\text { 20.342; } \\
0.013\end{array}$} & - & - \\
\hline Geniş aile & 128 & $99.19 \pm 5.50$ & & - & - \\
\hline \multicolumn{6}{|l|}{ Gelir durumu } \\
\hline Gelir giderden az (1) & 18 & $97.44 \pm 7.44$ & \multirow{3}{*}{$\begin{array}{l}\text { 3.772; } \\
0.024\end{array}$} & $2-3$ & 0.019 \\
\hline $\begin{array}{l}\text { Gelir gider ile dengeli } \\
\text { (2) }\end{array}$ & 236 & $98.48 \pm 5.67$ & & $2-1$ & 0.750 \\
\hline Gelir giderden fazla (3) & 86 & $96.46 \pm 6.11$ & & $1-3$ & 0.797 \\
\hline Toplam & 340 & $97.92 \pm 65.93$ & - & - & - \\
\hline
\end{tabular}

Tablo 2. Maternal Bağlanma Ölçeği İle İlişkisi Olduğu Düşünülen Gebelik İle İlgili Bazı Özellikler

\begin{tabular}{|c|c|c|c|}
\hline \multirow[t]{2}{*}{ Gebelik İle İlgiliÖzellikler } & \multirow[b]{2}{*}{$\mathbf{n}$} & \multicolumn{2}{|c|}{ Maternal Bağlanma Ölçeği } \\
\hline & & Ölçek puan & $\begin{array}{c}\text { Test değeri } \\
\text { F/T; p }\end{array}$ \\
\hline \multicolumn{4}{|l|}{ Gebelik sayısı } \\
\hline (1) & 91 & $97.46 \pm 5.63$ & \multirow{4}{*}{$2.377 ; 0.070$} \\
\hline 2 & 99 & $97.18 \pm 6.07$ & \\
\hline 3 & 98 & $98.12 \pm 5.93$ & \\
\hline $4 \quad(4)$ & 52 & $99.73 \pm 5.93$ & \\
\hline \multicolumn{4}{|c|}{ Gebeliğe bağlı sorun yaşama durumu } \\
\hline Hayır & 318 & $97.99 \pm 5.82$ & \multirow{2}{*}{$0.825 ; 0.511$} \\
\hline Evet & 22 & $96.91 \pm 7.43$ & \\
\hline \multicolumn{4}{|l|}{ Gebeliğin planlı olma durumu } \\
\hline Hayır & 61 & $98.31 \pm 6.79$ & \multirow{2}{*}{$\begin{array}{c}-0.806 \\
0.421\end{array}$} \\
\hline Evet & 279 & $97.83 \pm 5.73$ & \\
\hline
\end{tabular}


Annelerin, \%49.7' si doğum sürecini oldukça zor ve kötü olarak tanımlarken, \%48.2' si müdahaleli vajinal doğum yaptı. Annelerin doğum süreci ile ilgili özelliklerine yönelik bilgiler Tablo 3'de verilmiştir. Doğum sonu dönemde maternal bağlanma düzeyi ile ilişkili olduğu düşünülen bazı özellikler Tablo 4'de verilmiştir.

Tablo 3. Maternal Bağlanma Ölçeği İle İlişkisi Olduğu Düşünülen Doğum Süreci İle İlgili Bazı Özellikler

\begin{tabular}{|c|c|c|c|c|c|}
\hline \multirow{2}{*}{$\begin{array}{c}\text { Doğum Süreci İle İlgili } \\
\text { Özellikler }\end{array}$} & \multirow[b]{2}{*}{$\mathbf{n}$} & \multicolumn{4}{|c|}{ Maternal Bağlanma Ölçeği } \\
\hline & & Ölçek puan & $\begin{array}{c}\text { Test değeri } \\
\text { F/T; p }\end{array}$ & $\begin{array}{c}\text { Çoklu } \\
\text { karşılaştırma }\end{array}$ & $\mathbf{p}$ \\
\hline \multicolumn{6}{|l|}{ Doğum süreci } \\
\hline Oldukça zor ve kötü (1) & 49 & $98.18 \pm 5.50$ & \multirow{3}{*}{$\begin{array}{r}3.108 \\
0.046\end{array}$} & $2-3$ & $\mathbf{0 . 0 3 7}$ \\
\hline Zor (2) & 122 & $96.87 \pm 6.57$ & & $2-1$ & 0.385 \\
\hline Çok rahat ve kolay (3) & 169 & $98.59 \pm 5.46$ & & $1-3$ & 0.902 \\
\hline \multicolumn{6}{|l|}{ Doğum şekli } \\
\hline $\begin{array}{l}\text { Müdahalesiz vajinal } \\
\text { doğum (1) }\end{array}$ & 16 & $99.88 \pm 5.62$ & \multirow{3}{*}{$\begin{array}{c}2.031 ; \\
0.358\end{array}$} & - & - \\
\hline $\begin{array}{l}\text { Epizyotomili/ suni sancılı } \\
\text { vajinal doğum (2) }\end{array}$ & 164 & $97.67 \pm 6.48$ & & - & - \\
\hline Sezaryen (3) & 160 & $97.98 \pm 5.93$ & & - & - \\
\hline Total & 340 & $97.92 \pm 65.93$ & - & - & - \\
\hline
\end{tabular}

Tablo 4. Maternal Bağlanma Ölçeği İle İlişkisi Olduğu Düşünülen Doğum Sonu Döneme Ait Bazı Özellikler

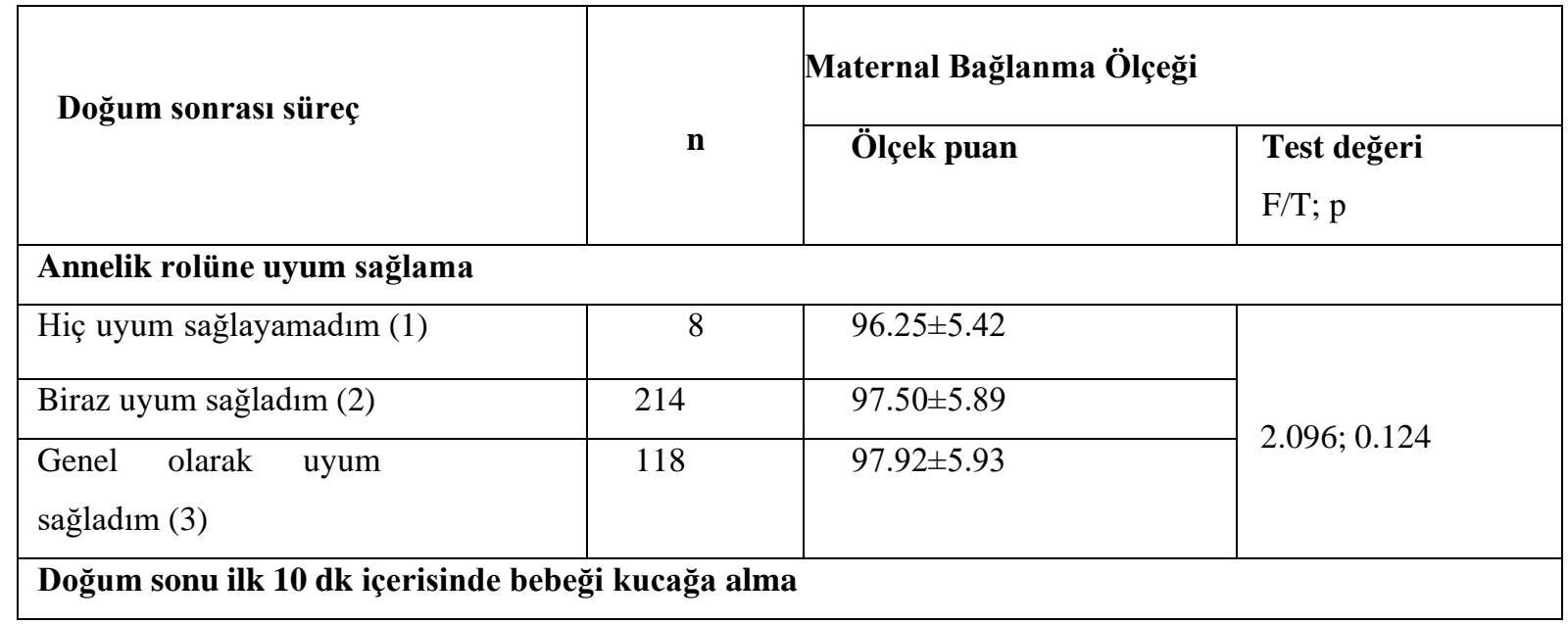




\begin{tabular}{|c|c|c|c|}
\hline Hayır & 75 & $97.11 \pm 5.88$ & \multirow{2}{*}{$5.343 ; 0.000$} \\
\hline Evet & 265 & $99.15 \pm 5.93$ & \\
\hline \multicolumn{4}{|c|}{ Bebeğe bakım konusunda endişe yaşama durumu } \\
\hline Hayır & 288 & $99.12 \pm 6.01$ & \multirow[t]{2}{*}{$6.760 ; 0.000$} \\
\hline Evet & 52 & $65.77 \pm 5.34$ & \\
\hline Total & 340 & $97.92 \pm 65.93$ & \\
\hline
\end{tabular}

\section{TARTIŞMA}

Anneler ve bebeklerin sağlıklı bir iletişimde bulunarak bebeklerinin ihtiyaçlarını gidermede birincil rol almaları maternal bağlanmayı etkileyebilmektedir. Bu durum da annelerin doğum sonrası fiziksel ve ruhsal olarak kendilerini yeterli hissetmeleriyle mümkündür. Çalışmamızda anne yaşı azaldıkça maternal bağlanma düzeyinin azaldığ 1 bulunmuştur $(\mathrm{p}<0.05)$. Çalışmamıza benzer olarak Çınaklı ve Arslantaş'in adölesan olan ve olmayan annelerde yaptıkları çalışmada adölesan annelerde maternal bağlanma düzeyleri daha düşük bulunmuştur (14). Yaş arttıkça maternal bağlanma düzeyinin artmas1 annelerin doğum tecrübelerinin artmasıyla, annelik rolü için kendilerini hazır hissetmeleriyle ve hem ruhsal hem de fiziksel olarak gelişme durumunun artmasıyla ilişkili olabilir (15). Buna karşın, literatürde yapılan bazı çalışmalarda ise yaş ve maternal bağlanma arasında anlamlı bir ilişki bulunamadığı görülmüştür (15-17).

Kadının eğitim düzeyi, sosyal yaşama etkin katılımının ve çocukların hem fiziksel hem de sosyal gelişimine etkisi olmaktadır. İş gücüne katılım, gelir düzeyini ve yaşam şeklini belirleyerek maternal bağlanma durumunu etkileyebilmektedir. Çalışmamızda demografik faktörlerden kadınların öğrenim durumu çoğunlukla lise olarak belirlenirken yine büyük bölümünün gelir getirici herhangi bir işte çalışmadığı belirlendi. Türkiye Nüfus ve Sağlık Araştırması (TNSA 2018)'nda kentte yaşayan 15-49 yaş grubundaki kadınların \%41'i lise ve üzeri eğitimini tamamladığı, \%64'ünün herhangi bir işte çalışmadığı, $\% 20.8$ ' inin hane halkı refahının orta düzeyde olduğu gösterilmiştir (19). Cuijlits ve arkadaşları yaptığı çalışmada ise yüksek eğitim düzeyinin doğum sonras1 bağlanmayı olumlu yönde etkileyen faktör olduğu sonucuna ulaşmışlardır (20). Çalışmamızda eğitim durumu azaldıkça maternal bağlanma puanları artmaktadır. Çalışmamızdaki bu bulgu eğitim durumu düşük popülasyonun fazla olmasından kaynaklaniyor olabilmekle birlikte, daha düşük eğitim düzeyine sahip olan annelerin iş gücüne katılımının daha az olması ve buna bağlı olarak bebekleriyle daha fazla 
zaman geçirerek anne bebek iletişiminin daha iyi olması olarak da açıklanabilir. Daha geniş popülasyonlu çalışmalarla bulgularımızın desteklenmesi gerektiği düşünülmektedir.

Etkili bir anne bebek ilişkisinde ailelerin temel gereksinimleri karşılayacak düzeyde sosyal ve ekonomik kaynaklara sahip olması önemlidir (17). Bu gereksinimleri karşılayamayan ailelerin bebekleriyle başarılı bağlar kurmasının daha zor olduğu bildirilmektedir (21). Çalışmamızda geniş aileye sahip olanların ve gelir gidere dengeli olan ailelerin maternal bağlanma düzeyleri daha yüksek bulunurken $(\mathrm{p}<0.05)$, kadının iş gücüne katılımı ile maternal bağlanma arasında farklılık bulunamamıştır ( $>0.05)$. Keskin ve Yağmur'un maternal bağlanmayı etkileyen faktörleri belirlemek için yaptıkları çalışmada ise kadının çalışmasının maternal bağlanmayı $\operatorname{artırdığ~}$ belirtilmiştir (15).

Kadınlarda gebelik ve doğum sonrası dönemde fiziksel ve psikolojik olarak birçok değişiklik meydana gelmekte ve ilk doğumlarını yapan kadınlar daha hassas olabilmektedir (12). Çalışmamızda, gebelik sayısı ile bağlanma arasında farklılık bulunamamıştır $(p>0.05)$. Dereli Yılmaz ve Kızılkaya Beji'nin prenatal bağlanmayı değerlendiren çalışmasında ise bizim çalışmamızdan farklı olarak multipar annelerin bağlanma düzeyinin daha düşük olduğu belirlenmiştir (22). Çalışmamızda gebelik sayısı ile maternal bağlanma arasında farklılık bulunamaması, kadınların her gebeliğinin ayrı ve kendine özgü olması ve bebeklerini kucaklarına aldıklarında ilk temasın verdiği heyecanın her bebekte yeniden oluşmasından kaynaklandığ düşünülebilir.

Bağlanmayı etkileyen önemli durumlardan biri ise gebelikte sağlı sorunları yaşanmasıdır. Gebelikte yaşanan sorunlar genellikle anne adayları için bir kriz olarak değerlendirilip ebeveynlik davranışlarını olumsuz etkilemektedir. Kadın kendini yetersiz hissedebilir ve depresif düşünceler yaşayabilmektedir (12). Gebelik döneminde sorun yaşayan kadınların anneliği kabulünün ve annelik rolüne adaptasyonun uzadığ belirtilmektedir (16). Pisoni ve ark. yüksek riskli ve normal gebelerde, prenatal faktörler ve sosyal destek sistemleri ile bağlanma arasındaki ilişkiyi karşılaştırdıkları çalışmalarında yüksek riskli olan grupta daha fazla anksiyete ve depresyonun görüldüğü, bağlanmada sorunlar yaşandığı belirlenmiştir (23). Koç ve ark. ise doğum şekli ve doğumda sorun yaşama durumunun annelik rolü kazanımını etkilemediğini belirlemiştir Çalışmamızda benzer şekilde, gebeliğe bağlı sorun yaşama, kontrollerine düzenli gitme ve gebeliğin planlı olma durumu ile 
annelerin ölçek puanları arasında farklılık bulunamamıştır $(\mathrm{p}>0.05)$.

Çalışmamızda doğum şekli ile maternal bağlanma arasında farklılık bulunamazken (p>0.05), doğum süreci zor olmayı, oldukça kolay ve rahat geçen annelerde maternal bağlanma daha yüksek belirlenmiştir $(p<0.05)$. Haratipour ve ark. yaptıkları çalışmada müdahalesiz vajinal doğum ile doğum yapan annelerin müdahaleli doğum yapan annelere göre bağlanma düzeyleri anlamlı düzeyde yüksek bulmuştur (24). Aynı şekilde Çetisli ve ark. sezaryen doğum yapan annelerin vajinal doğum yapan annelerden daha düşük maternal bağlanma gösterdiğini belirtmişlerdir (25). Çalışmamızla benzer şekilde doğum şekli ile maternal bağlanma arasında farklılık bulunmayan çalışmalar da bildirilmiştir $(26,27)$.

Erken dönemde ten tene temas ile anne ve bebek arası bağ olumlu etkilenmekte bebek kendini güvende hissetmekte buna bağl1 olarak oksitosin ve prolaktin hormonlarının salınımının artmasıyla emzirme de desteklenmektedir $(17,28)$. Adeli ve Aradmehr'in yaptıkları çalışmada da erken ten tene temasin anne bağlanma davranışları yönünde olumlu etkiye sahip olduğu bulunmuştur (29). Durualp ve ark. yaptığ 1 çalışmada bebeğini ilk $30 \mathrm{dk}$ içinde kucağına alan annelerin bağlanma düzeyleri daha yüksek bulunmuştur (17).
Çalışmamızda da literatüre benzer şekilde, doğum sonu ilk $10 \mathrm{dk}$ içerisinde bebeğini kucağına alan, bebeğine bakım konusunda endişe yaşamayan annelerin maternal bağlanma puanları daha yüksek bulunurken $(p<0.05)$, annelik rolüne uyum sağlama durumu ile bir farklılık bulunamamıştır $(\mathrm{p}>0.05)$.

\section{KAYNAKLAR}

1. Miller T. Annelik Duygusu: Mitler ve Deneyimler. İstanbul İletişim; 2010 .

2. Nacar EH, Gökkaya F. Bağlanma ve Maternal Bağlanma Konusunda Bir Derleme. Cyprus Turkish J Psychiatry Psychol. 2019; 1(1):49 55.

3. Mutlu C, Yorbik Ö, Tanju İA, Çelikel F, Sezer RG. Doğum Öncesi, Doğum Sırası ve Doğum Sonrası Etkenlerin Annenin Bağlanması ile İlişkisi. Anadolu Psikiyatr Derg. 2015; 16(6):442-50.

4. Baltacı N, Başer M. Riskli Gebelerde Yaşanan Anksiyete, Prenatal Bağlanma ve Hemşirenin Rolü. Dokuz Eylül Üniversitesi Hemşirelik Fakültesi Elektron Derg. 2020; 13(3):206-

12.http://www.deuhyoedergi.org.(Er işim Tarihi:2 Temmuz 2021)

5. Rollè L, Giordano M, Santoniccolo F, Trombetta T. Prenatal Attachment 
and Perinatal Depression: A Systematic Review. International Journal of Environmental Research and Public Health. 2020; 17(8):2644

6. Tichelman E, Westerneng $\mathrm{M}$, Witteveen AB, Van Baar AL, Van Der Horst HE, De Jonge A, et al. Correlates of Prenatal and Postnatal Motherto-İnfant Bonding Quality: A Systematic Review. PLoS One. 2019; 14(9). e0222998.

7. Bülez A, Ekti Genç R. Yenidoğan Ebeveyn İlişkisinin Başlatılması ve Geliştirilmesi. İzmir Kâtip Çelebi Üniversitesi Sağlık Bilim Fakültesi Derg. 2016; 2(1):33-6.

8. Feldman R, Weller A, Sirota L, Eidelman AI. Testing a Family Intervention Hypothesis: The Contribution of Mother-İnfant Skin To Skin Contact (Kangaroo Care) to Fmily İnteraction, Proximity, and Touch. J Fam Psychol. 2003; 17(1):94-107.

9. Karakaş NM, Dağlı FŞ. Bebeklerde Bağlanmanın Önemi Ve Etkileyen Etmenler. Turk Pediatr Ars. 2019; 54(2):76-81.

10. Gibbs BG, Forste R, Lybbert E. Breastfeeding, Parenting, and Infant Attachment Behaviors. Matern Child Health J. 2018; 22(4):579-88.

11. Muslu SN, Bat Tonkuş M. Maternal Bağlanma ve İlişkili Faktörler.
Journal of Medical Science. 2021; 2(2):32-40.

12. Kınık E， Özcan H. Maternal Bağlanmayı Etkileyen Faktörler ve Primiparlarda Maternal Bağlanma Durumu. Sağlik Profesyonelleri Araştırma Derg. 2020; 2(1):47-53.

13. Koç Ö, Özkan H, Bekmezci H. Annelik Rolü ve Ebeveynlik Davranışı Arasındaki İlişkinin Değerlendirilmesi. İzmir Dr Behçet Uz Çocuk Hast Derg. 2016; 6(2):143-50.

14. Çınaklı Ş, Arslantaş H. Adölesan Olan ve Olmayan Annelerde Çocukluk Çağı Travmaları, Postpartum Depresyon ve Maternal Bağlanma. Cukurova Med J. 2021; 46(2):789-800.

15. Keskin F, Yagmur Y. The Factors Affecting Maternal Attachment in Eastern Turkey. Int $\mathbf{J}$ Caring Sci. 2020; 13(2):858-66.

16. Bilgin Z, Alpar E. Kadınların Maternal Bağlanma Algısı ve Anneliğe İlişkin Görüşleri. HSP. 2018; 5(1):6-15.

17. Durualp E, Kaytez N, Girgin BA. Evlilik Doyumu ve Maternal Bağlanma Arasındaki İlişkinin İncelenmesi. Anadolu Psikiyatr Derg. 2017; 18(2):129-38.

18. Kavlak O, Şirin A. Maternal Bağlanma Ölçeği'nin Türk 
Toplumuna

Uyarlanması.

Uluslararası İnsan Bilim Derg. 2009; 6(1):189-202.

19. TürkiyeNüfusveSağlıkAraştırması( TNSA). 2018.

http://www.hips.hacettepe.edu.tr/tns a2018/rapor/TNSA2018_ana_Rapor .pdf.(Erişim Tarihi:4 Temmuz 2021)

20. Cuijlits I, Van De Wetering AP, Endendijk JJ, Van Baar AL, Potharst ES, Pop VJM. Risk and Protective Factors For Pre and Postnatal Bonding. Infant Ment Health J. 2019; 40(6):768-85.

21. Shin H, Park YJ, Kim mi ja. Predictors of Maternal Sensitivity During the Early Postpartum Period. J Adv Nurs. 2006; 55(4):425-34.

22. Dereli Yılmaz S, Kızılkaya Beji N. Gebelerin Stresle Başa Çıkma, Depresyon ve Bunları Etkileyen Faktörler. Genel Tip Derg. 2010; 20(3):99-108.

23. Pisoni C, Garofoli F, Tzialla C, Orcesi S, Spinillo A, Politi P, et al. Prenatal Attachment During Pregnancy at Risk for Preterm Delivery. J Matern Neonatal Med. 2016; 29(5):771-6.

24. Ebrahimi E, Haratipour H, Partash $\mathrm{N}$, Bolbolhaghighi N. Nonphysiological and Physiological Delivery Method: Comparison of Maternal Attachment Behaviors and
Anxiety. J Caring Sci. 2021; 10(1):37-42.

25. Çetişli NE, Arkan G, Top ED. Maternal Attachment and Breastfeeding Behaviors According to Type of Delivery in the İmmediate Postpartum Period. Rev Assoc Med Bras. 2018; 64(2):164-9.

26. Carlander AKK, Edman G, Christensson K, Andolf E, Wiklund I. Contact Between Mother, Child and Partner and Attitudes Towards Breastfeeding in Relation to Mode of Delivery. Sex Reprod Healthc. 2010; $1(1): 27-34$.

27. Figueiredo B, Costa R, Pacheco A, Pais Á. Mother to İnfant Emotional İnvolvement at Birth. Matern Child Health J. 2009; 13(4):539-49.

28. Moore ER, Anderson GC. Randomized Controlled Trial of Very Early Mother-Infant Skin-toSkin Contact and Breastfeeding Status. J Midwifery Women's Heal. 2007; 52(2):116-25.

29. Adeli M, Aradmehr M. A Comparative Study of Maternal Neonatal Abdominal and Kangaroo (skin-to-skin) Skin Contact İmmediately After Birth on Maternal Attachment Behaviors up to 2 Months. J Educ Health Promot. $2018 ; 7: 42$. 